\title{
Definition, capabilities and components of a terrestrial carbon monitoring system
}

\section{Tristram O West*1, Molly E Brown², Riley M Duren ${ }^{3}$, Stephen M Ogle ${ }^{4}$ \& Richard H Moss ${ }^{1}$}

Research efforts for effectively and consistently monitoring terrestrial carbon are increasing in number. As such, there is a need to define carbon monitoring and how it relates to carbon cycle science and carbon management. There is also a need to identify capabilities of a carbon monitoring system and the system components needed to develop the capabilities. Capabilities that enable the effective application of a carbon monitoring system for monitoring and management purposes may include: reconciling carbon stocks and fluxes, developing consistency across spatial and temporal scales, tracking horizontal movement of carbon, attribution of emissions to originating sources, cross-sectoral accounting, uncertainty quantification, redundancy and policy relevance. Focused research is needed to integrate these capabilities for sustained estimates of carbon stocks and fluxes. Additionally, if monitoring is intended to inform management decisions, management priorities should be considered prior to development of a monitoring system.

The term carbon monitoring has been used to define a broad array of methods, projects and programs across many scales and disciplines. Use of the term has increased over the past decade as the diversity of disciplines and communities working on climate issues broaden. Consensus on the definition and capabilities of a carbon monitoring system (CMS) is not well established, thereby potentially impeding its development.

The objectives of this paper are to provide clarification on, and insight into, the following questions: what is carbon monitoring? What capabilities should be included in a CMS? What system components are needed to meet the proposed capabilities? It is our expectation that by discussing these questions we can help contribute to the development of a comprehensive CMS and increase the successful application of such a system. We begin by defining carbon cycle science, carbon monitoring and carbon management. We then discuss capabilities that are likely needed from a CMS and components of a CMS that are needed to build the capabilities. Our discussion of capabilities and components is focused on terrestrial ecosystems, although we acknowledge that riverine and oceanic carbon monitoring will play a key role in any CMS.

Carbon cycle science, monitoring \& management Many programs and projects currently exist to conduct research on carbon cycling, carbon monitoring and carbon management. We define some of these research activities here and discuss the differences and commonalities among them in an effort to understand how they may be used together in the development of a CMS.

Carbon cycle science is the study of biogeochemical processes that influence flows of carbon through and among carbon reservoirs, including the terrestrial biosphere, atmosphere and oceans. Carbon flows include vertical fluxes, measured as a mass or volume of $\mathrm{CO}_{2}$ per unit area and per unit time, and horizontal displacement of carbon including the import and export of commodities and the transport of carbon

Joint Global Change Research Institute, Pacific Northwest National Laboratory, 5825 University Research Court, College Park, MD 20740, USA

${ }^{2}$ National Aeronautics and Space Administration, Goddard Space Flight Center, Biospheric Sciences Laboratory, Greenbelt, MD 20771, USA

${ }^{3}$ National Aeronautics and Space Administration Jet Propulsion Laboratory and California Institute of Technology, 4800 Oak Grove Dr, Pasadena,

CA 91109, USA

${ }^{4}$ Natural Resource Ecology Laboratory, Colorado State University, Fort Collins, CO 80523, USA

*Author for correspondence: Tel.: +1 301314 6705; E-mail: tristram.west@pnnl.gov 


\section{Key terms}

Carbon monitoring: Sustained measurements or estimates of carbon dynamics. A carbon monitoring system would include sustained estimates of all carbon dynamics that are needed to estimate total carbon exchange between the biosphere and atmosphere. It is proposed here that such a system include capabilities that are useful for carbon management and other decision-making purposes.

Bottom-up estimation methods: Generated by summing carbon emissions and sinks from all relevant carbon-containing or carbon-emitting entities. Bottom-up estimates may include the use of inventory-based models, ecosystem process models or site-specific measurements from eddy covariance flux towers. In many of these cases, satellite remote sensing of land cover or plant physiological processes is used to scale-up or spatially distribute estimates of carbon stocks and fluxes. Bottom-up estimates help attribute changes in stocks and fluxes to activities or entities.

Top-down estimation methods: Generated by estimating the total net exchange of $\mathrm{CO}_{2}$ between the biosphere and atmosphere. While attribution of emissions is difficult using top-down methods, an estimate of total net carbon exchange can verify or constrain bottom-up estimates Top-down estimates use atmospheric measurements combined with atmospheric transport and inversion models.

Carbon accounting: Includes methods that reconcile carbons stocks and fluxes across space and time. These methods ensure that components included in different bottom-up and top-down estimates are comparable, and that measurements generated at small time intervals (e.g., every 30 s) are comparable to estimates generated annually. Carbon accounting methods also change based on project objectives or stakeholder interest. For example, terrestrial fluxes that are compared with atmospheric fluxes differ from life cycle analyses of terrestrial stock changes that may be relevant for decision-making purposes. In both cases, the initial measurements and estimates are the same, but the accounting differs. through hydrologic systems. The amount of carbon in a reservoir, commonly referred to as a carbon stock, includes carbon stored in biomass, soils, oceans, forest products or other physical entities. Terrestrial carbon cycle science has largely focused on how carbon stocks and fluxes may change with changes in climate (e.g., temperature and precipitation) and land management (e.g., agriculture, production forestry and land-use change). Studying these changes is performed through a combination of observation and process-based modeling. Experiments such as the US Department of Energy's (DOE's) Free-Air $\mathrm{CO}_{2}$ Enrichment and the Next Generation Ecosystem Experiment help to quantify changes in carbon stocks and fluxes by improving our understanding of the impact of climate-related factors on plant physiology and ecosystem function [101]. The US Department of Agriculture established the GRACENET program to quantify effects of agricultural management on $\mathrm{CO}_{2}$ and other GHG emissions [1]. Individual and networked field experiments of this nature improve our understanding of carbon dynamics, but they are not intended to provide consistent and sustained estimates of carbon dynamics over large spatial extents.

Carbon monitoring is intended to provide sustained estimates of carbon stocks and fluxes over large spatial extents. Carbon monitoring of some terrestrial stocks and fluxes already occurs, and may include national and global inventories [102-104], global and regional atmospheric inversions [2,3], soil mapping [4] and process-based ecosystem modeling [5]. However, no comprehensive CMS currently exists that estimates natural and anthropogenic carbon stocks and fluxes consistently across ecosystems and economic sectors, while doing so in a sustained manner. The absence of a CMS limits science and policy communities in their ability to regularly assess past and current carbon stocks and fluxes, and also limits their ability to estimate future fluxes based on projected changes in land use and energy production. Research programs and efforts for transitioning to a sustained delivery of policy-relevant, applied science datasets are needed to bring about such a system. A CMS research program was recently initiated by the US National Aeronautics and Space Administration to characterize, quantify and predict global carbon sources and sinks, while also establishing the accuracy, quantitative uncertainties, and utility for supporting national and international policy, regulatory and management activities [105]. Other multiagency and international programs focus on the compilation and development of carbon stock and flux estimates, such as the Global Carbon Project [6], Regional Carbon Cycle Assessment and Process [7], GEOCARBON [106] and the National Climate Assessment [8]. However, the focus of some of these programs is on the synthesis of existing data, and not on fundamental research to develop a functional CMS. In programs where CMS research is the focus, there remains an opportunity to define the ultimate capabilities and components of a CMS.

Carbon management refers to human activities used to alter baseline carbon stocks and fluxes. Carbon stocks and fluxes are affected by, for example, landcover change, land management, fossil fuel production and combustion, or geoengineering of the carbon cycle. Management of carbon requires the ability to track and quantify carbon throughout human-dominated systems (e.g., impacts of climate on forest production, demand for forest products, and use and lifetime of forest products). Assessing these interactions requires the ability to simulate indirect or tangential impacts on carbon sources and sinks due to carbon-management activities. In effect, monitoring for management purposes will require more system components, and a more thorough mechanistic understanding of these components, than monitoring for the sole objective of quantifying carbon stocks and fluxes [9].

In summary, carbon cycle science provides the understanding of carbon dynamics needed to develop a CMS. Carbon monitoring can provide the system needed to regularly generate carbon stock and flux estimates, and to help inform carbon-management strategies. For example, the ongoing North American Carbon Program [10] has recently conducted analyses comparing forward models, inventory estimates and atmospheric estimates to better understand, constrain and estimate carbon stocks and fluxes [5,11] [OgLe SM, Davis K, Lauvaux T etal. Verifying greenhouse gas emissions inventories with atmospheric $\mathrm{CO}_{2}$ measurement data; Submitted]. A more advanced CMS would generate 
carbon trends on a regular basis, identify and develop the datasets and models needed for these estimates, and ensure relevancy of the system to societal carbon-related issues including carbon management. Identifying a suite of capabilities needed from a CMS is the first step in development.

\section{Capabilities of a CMS}

Identification of needed capabilities for a CMS will likely be an ongoing process; however, some capabilities can be identified now. These capabilities represent system functions that are needed to obtain consistent carbon stock and flux estimates on a regular basis, and that can be used to inform decision-makers regarding carbon management or policy-related activities. We propose here that these capabilities may include, but are not limited to, reconciling carbon stocks and fluxes, developing consistency across scales, quantifying movement and transport of carbon, attributing carbon emissions and sinks to respective sources, cross-sectoral accounting, uncertainty quantification, redundancy in estimates and policy relevance. These capabilities are explained below.

\section{- Reconciling carbon stocks \& fluxes}

Estimation of terrestrial carbon stocks and fluxes is a key CMS capability. Estimation can be conducted using bottom-up and top-down methods. Bottom-up estimation methods may include inventory-based modeling [11,12] [Ogle SM, Davis K, Lauvaux T et al. Verifying GREENHOUSE GAS EMISSIONS INVENTORIES WITH ATMOSPHERIC $\mathrm{CO}_{2}$ measurement data; Submitted], upscaling of eddy covariance measurements $[13,14]$, remote sensing applications [15] and process-based modeling [5]. Topdown estimation methods may include atmospheric concentration measurements and inversion modeling systems $[2,3,16,17]$. Some of these methods estimate fluxes, while other methods estimate stocks and changes in stocks. Quantification of stocks provides an estimate of what is currently sequestered in the terrestrial biosphere. Changes in stocks can be used to estimate fluxes or net emissions to the atmosphere, and such methods are predominantly employed by inventory-based models. In most cases, estimating net emissions of carbon to the atmosphere is the ultimate goal, and net emissions are what many countries currently report under the UNFCCC [18]. However, changes in regional carbon stocks do not always equate to the true net flux. For example, changes in forest stocks need to consider carbon stored in forest products in order to accurately estimate flux within a given region $[19,20]$. Similarly, agricultural flux estimates must consider the harvest and release of carbon over space [12]. The time over which stocks change also influences the flux estimate. In the case of herbaceous annual crops, biomass is often considered to result in zero net emissions over a 1-year time period [18]. However, it is not handled consistently across national inventories or model disciplines. For example, the US inventory considers herbaceous biomass to result in net zero annual emissions, while the UK inventory assigns a stock value to annual herbaceous crops.

Existing carbon accounting methods at the national $[19,21]$, continental [22,23] and international [24,25] scales may have to be reconciled during CMS development. For example, the Intergovernmental Panel on Climate Change guidelines do not include $\mathrm{CO}_{2}$ emissions from livestock, because it is assumed to be part of the short-term cycle of plant growth, consumption and respiration [24,25]. However, emissions sources and sinks are needed to complete regional carbon budgets, even if associated net global emissions are zero or close to zero. Other potential carbon accounting issues have also been documented and are often followed by a request for further consideration [26,27]. Reconciling carbon accounting methods and terminology will help in reconciling stocks and fluxes, and will be an essential part of CMS development [28,29].

\section{- Maintaining consistency across scales}

Different methods of observing and estimating carbon dynamics often result in estimates of carbon stocks and fluxes at different spatial and temporal scales. Each of these scales serve a purpose and address a research objective in the science domain. Coarse-scale estimates capture aggregated fluxes over large regions that, in theory, capture all carbon sources and sinks within the region. Higher resolution estimates often attempt to capture individual sources and sinks (e.g., forest stands, crop fields and power plants). Problems arise when higher resolution land management models use, for example, 30-m resolution satellite-derived land cover data, while global carbon-climate models use $0.5^{\circ}$ resolution landcover data, resulting in significant differences in carbon estimation. Furthermore, integrated assessment models that are predicting future fluxes often utilize data in land areas based on geopolitical inventory data. Hence, three research disciplines are using three different baseline land cover areas.

If a CMS is built to monitor land cover over large regions, while maintaining capabilities to attribute emissions, consistency among land classes and emissions entities need to exist across scales. We are not suggesting that all models use the same input datasets, as this may not be possible due to model structure and computing limitations. We are, however, suggesting that inconsistencies in model input be understood and reconciled where possible [30]. Integrating different resolution land products at different scales of analysis 
may require a multi-scalar approach, or the upscaling of carbon stock measurements with the downscaling of geopolitical inventory data [31]. Throughout the multi-scalar approach, it will be essential that estimates of land area, carbon stocks and carbon fluxes are consistent across scales. In other words, estimates at higher resolutions should sum to equal estimates at coarser resolutions. At a minimum, higher resolution estimates should fit within the uncertainty range of coarser resolution estimates.

\section{- Tracking movement \& transport of carbon}

Horizontal displacement of carbon can occur as part of ecosystem processes or by direct human activity. Horizontal displacement resulting from ecosystem processes includes soil erosion [32] and riverine transport [33]. These processes are key to closing terrestrial carbon budgets. Horizontal displacement from direct human activity includes transport of forest and agricultural commodities that influence regional estimates of carbon stocks and fluxes [12,34]. Movement of carbon-containing commodities is driven by economic supply and demand, and quantification of commodity movement helps to understand how and why natural resources are being used and how they might be managed. Estimates of horizontal carbon displacement are also needed to understand carbon footprints, life cycle analyses, and carbon budgets of cities and geopolitical areas. Linking production of carbon-related commodities with end users of these commodities is important for evaluating mitigation options that are strongly influenced by supply chains. Movement of carbon can be estimated from economic activity, including national and international commodity trading, and by tracking the physical movement of biomass and commodities through the use of national and international transportation data.

\section{- Attribution}

Attribution of carbon emissions to their source is a key CMS capability because it provides quantitative information on the causes of change in carbon stocks and fluxes. Emissions attribution can refer to the ability to differentiate biogenic emissions from fossil fuel (i.e., geogenic) emissions, anthropogenic emissions from natural emissions and direct anthropogenic emissions from indirect anthropogenic emissions. Attribution can also refer to the ability to identify emissions sources, thereby enabling the capacity to manage carbon at national, regional and local scales [35]. This may include the ability to quantify the contribution of forest harvesting to net global emissions, the contribution of the transportation sector to net emissions or the land-management practices responsible for changes in regional soil carbon stocks.
Monitoring at a scale that enables attribution may require the ability to classify land cover and land use at higher resolutions and also model carbon dynamics at higher resolutions [36,37]. Modeling carbon dynamics at global scales tends to be coarse and not particularly useful for attributing carbon sources or sinks to individual entities [38]. For example, one or two land classes that represent croplands do not enable detailed decisions on land management at a subnational scale, given that most countries have different land classes, different commodities and multiple options for managing commodities. Global-scale models are, however, important for estimating global carbon dynamics and climate feedbacks. By contrast, nationalscale models often have higher resolution data that help attribute sources and sinks in a global context [39]. National-scale models tend to be more useful for informing policy decisions because of their ability to connect carbon stocks and flows to ground-based physical entities.

Modeling carbon dynamics of land cover and land management at higher resolutions often requires downscaling of national or regional level data regarding land management and production inputs. Downscaling of inventory data on forests, crops, livestock and human populations can be conducted using satellite-based land products to improve spatial representation while maintaining the accuracy of ground-based estimates $[31,40]$. Downscaling of inventory data enables the spatial integration of land use and management activities (e.g., harvest cycles and production inputs) with environmental factors (e.g., soil attributes and water availability) to improve estimates of carbon stocks and fluxes, while attributing carbon dynamics to respective land-management activities.

\section{- Cross-sectoral accounting}

In current national [18] and international inventories [25], emissions are separated into categories such as industrial, agriculture, land-use change and forestry, and waste. This categorization is sufficient to obtain national emissions estimates by sector, but it does not allow for full GHG accounting. In other words, if land changes from forest to cropland, fertilizer production in the industrial sector is also impacted, as are decomposition of food in the waste sector, increased emissions from farm equipment in the transportation sector and release of soil carbon over time from cultivation. Such analyses, often referred to as full GHG accounting or life cycle analyses, are currently conducted on a project basis [41], but a systematic data-modeling framework to enable geospatial GHG accounting from local to continental scales does not currently exist. Data layers in a CMS that represent estimates and attribution of carbons 
stocks and fluxes would likely provide the infrastructure needed for cross-sectoral accounting.

\section{- Uncertainty}

Estimating statistical uncertainty associated with estimates of carbon stocks and fluxes is needed so that decision-makers understand the level of confidence associated with estimates prior to establishing management strategies [42,43], and so that researchers can compare and integrate different methods of estimation to further develop a comprehensive CMS [11,44] [OGLE SM, Davis K, Lauvaux T et al. Verifying greenhouse gas emissions inVentories with atmospheric $\mathrm{CO}_{2}$ measurement data; Suвmitтеd]. Uncertainty has been estimated differently in carbon-related projects. Uncertainty has been estimated from the spread of results from multiple models, referred to as a multimodel ensemble; by applying probability density functions to model parameters and generating an estimate of uncertainty via error propagation; by comparison between two independent datasets (e.g., process-based model results vs flux tower estimates), similar to an empirical approach [45]; and expert opinion. These methods differ in whether they are estimating uncertainty in model structure, model driver data or model parameters. In many cases, uncertainty estimates are not provided with driver data, nor are uncertainty estimates provided with key model parameters. Datacompilation efforts could be initiated that would help develop uncertainty estimates for key model parameters. In addition to such efforts, a review of how uncertainty is handled within the different components of a CMS is needed, as is a concerted effort to establish consistent uncertainty quantification methods for application within a CMS.

\section{- Redundancy}

Redundancy of stock and flux estimates is needed within a CMS to improve confidence and reduce uncertainty in the estimates, and to identify knowledge gaps and errors. An example of this would be fossil fuel emissions from the US DOE Energy Information Administration that are based on fuel production [46] versus emissions from the Vulcan model [47] that are based on fuel consumption. The two are relatively similar in their estimates, thereby providing confidence in the overall estimate, while the latter uses higher resolution capabilities for attribution and management.

The North American Carbon Program has been focused on the reconciliation of top-down and bottom-up methods in order to improve final estimates and reduce uncertainty [11] [Ogle SM, Davis K, Lauvaux T et al. Verifying greenhouse gas emissions inVentories with atmospheric $\mathrm{CO}_{2}$ measurement data; Submitted]. Field measurements, inventory data, remote sensing methods and atmospheric inversion models can all provide redundancy in estimates. However, their integration for improving the final estimate can inhibit them from providing the necessary redundancy. A balance of integration and redundancy should be sought.

\section{- Policy relevance}

There is a need for carbon management to reduce anthropogenic contributions to climate change and to sustainably meet the needs of a growing human population. In the absence of sound scientific information, carbon management may not be effective. It is therefore key to understand what information is needed and to use this understanding to inform development of a CMS [48]. Capabilities of a CMS that were previously discussed contribute to the scientific development of a CMS, but do not identify current management activities that might benefit from CMS information and data. Methods exist for identifying and prioritizing decision support needs, and these methods have been applied to carbon-climate research efforts and proven useful in guiding the development of future research [49]. A dedicated effort to guide the development of a CMS using similar methods may help ensure the use of carbon-monitoring data by the policy and management communities.

While formal methods to identify policy and management needs, and to engage relevant stakeholders, are not employed here, there are some preliminary applications of a CMS that can be identified. A CMS can be used to analyze carbon-related policy and management issues, and these analyses may include:

- Evaluating mitigation targets;

- Trading carbon in carbon markets;

- Measuring, reporting and verifying emissions associated with regional or global emissions agreements, such as the effort for REDD.

Outside of carbon-related issues, there are numerous issues that require data and analyses related to biomass, energy use, food security and land management that could potentially be addressed using a CMS. These analyses may include:

- Integrated management of land, water and energy;

- Effectiveness of land and wildlife conservation programs;

- Optimum land management for food, feed, fiber and biofuels;

- Understanding and quantifying drivers of land-use change. 
A CMS can be used for these latter analyses immediately and regardless of whether broader carbon policies and emissions targets are implemented.

Most policy-related issues require an understanding and quantification of future change. Estimating future activities that impact carbon emissions, along with future scenarios of carbon stocks and fluxes, often requires data on production costs, net profits, land rates and the ability to model economic dynamics, and land-use change. These modeling capabilities are often found in natural resource economic models [50,51] and integrated assessment models [52,53]. Development of a CMS with economic forecasting capabilities would help address many of the aforementioned policy and management needs. At a minimum, an understanding of the data needed by economic models prior to the development of a CMS would be advantageous for future integration and research applications. For example, a recent analysis

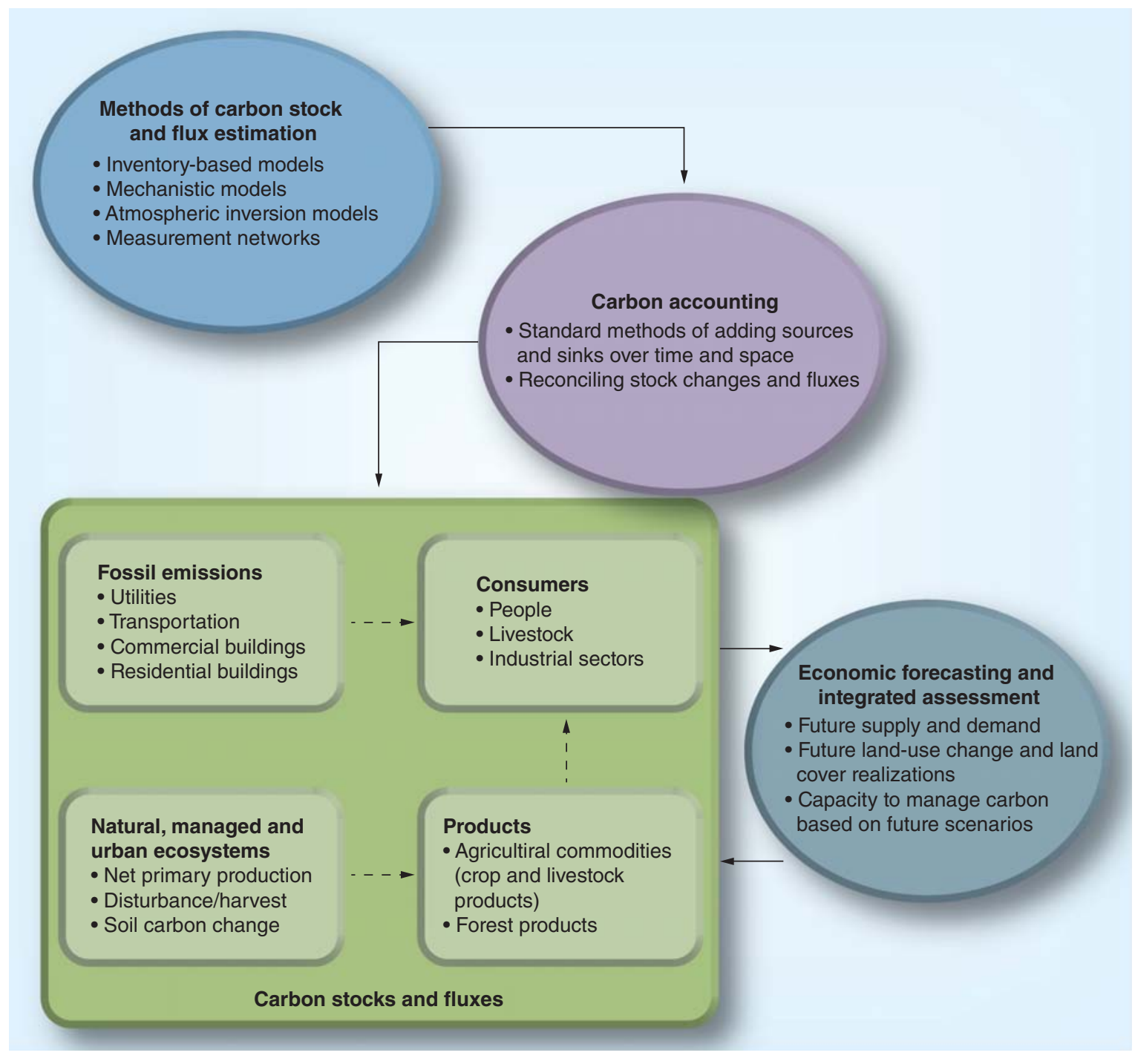

Figure 1. Components of a carbon monitoring system capable of satisfying multiple objectives. Represents emissions from fossil (geogenic) and biogenic sources, while attributing emissions to sources and tracking the use of carbon through production and consumption. Vertical fluxes and horizontal displacement of carbon are represented. Science-based methods of stock and flux estimation are filtered through existing carbon-accounting methods to ensure that the system is compatible with current national and international accounting methods or that follow previously agreed-upon guidelines. Integrated assessment can be used to estimate future changes in carbon stocks and fluxes. Squares represent sources and sinks of carbon; dashed arrows represent horizontal displacement of carbon. Circles represent methods of estimating stocks and fluxes; single arrows represent movement of data. 
illustrated how integrated assessment models and life cycle analyses come to different conclusions regarding the rate of bioenergy deployment and subsequent impacts on net emissions [54]. This particular analysis suggests the need for a top-down and bottom-up modeling approach for bioenergy deployment, and this approach is very similar to what can be developed within a CMS [54].

\section{Components \& implementation of a CMS}

After expected capabilities of a CMS are outlined, components need to be integrated in order to develop the capabilities. Integration of system components is perhaps the most challenging task in developing a CMS. Highlevel integration of system components is illustrated in Figure 1 to suggest what might be included in a CMS and how these components would function together. Components were chosen to meet aforementioned capabilities. Redundancy is built into the system and is fulfilled by two or more methods of carbon flux estimation. Methods are comprised of both bottom-up and top-down estimates. Bottom-up estimates serve to attribute emissions sources and sinks to the responsible entity. Summing emissions from entities (e.g., utilities, transportation, and so on) provides a net total estimate for individual economic sectors (e.g., fossil emissions). Combining these estimates with top-down estimates provides numbers for total stocks and fluxes over large regions. Cross-sectoral accounting can be conducted by developing links between emissions sources and sinks, including links between manufacturing, production and consumption (Figure 1). These links are analogous to a horizontal road network of carbon movement. Finally, policy relevance is identified and served by economic forecasting and integrated assessment modeling.
Once the production (e.g., net primary production or mining of fossil fuels), transport, consumption, and net emissions of carbon is linked to social and economic drivers, nearly any future scenario can be analyzed to assess implications on carbon stocks and fluxes. Datasets and model technologies currently exist for many of the CMS components previously discussed. Therefore, the challenge is not necessarily to develop the components and tools, but to organize the components to work as a single system. This requires a science-based understanding of how the components fit together, and research on how tools (e.g., models, data processing steps, and so on) can be reformatted to function together.

\section{Future perspective}

Research on carbon cycle science and on carbon management has matured greatly over the past decade. Development of a CMS could serve a unique role to generate sustained and consistent estimates of carbon stocks and fluxes, and to bridge carbon cycle science and carbon-management activities. This bridge would be formed by developing capabilities for emissions attribution, horizontal displacement of carbon and crosssectoral accounting. Combined with underlying social and economic drivers, these capabilities provide improved estimates of past and future changes in carbon stocks and fluxes. Building redundancy into the system and including estimates of uncertainty also improves estimates of carbon stocks and fluxes while providing a measure of confidence in the estimates. System components needed to develop the capabilities described here will likely include satellite remote sensing of land cover, inventory-based modeling methods, international accounting guidelines, atmospheric and ecological modeling of carbon dynamics,

\section{Executive summary}

Carbon research terminology

- Defining carbon cycle science, carbon monitoring and carbon management is helpful to understand and communicate differences among these research areas.

- Carbon cycle science research tends to focus on understanding biogeochemical processes that influence carbon stocks and fluxes; carbon monitoring research focuses on how to develop consistent and sustained measurements of carbon stocks and fluxes, based on carbon cycle science; and carbon management focuses on understanding how human activities have influenced and will influence changes in carbon stocks and fluxes associated with management activities.

Carbon monitoring system capabilities

- Carbon monitoring system (CMS) capabilities define the functional requirements for monitoring carbon stocks and fluxes.

- CMS capabilities may include: reconciling carbon stocks and fluxes; developing consistency across spatial and temporal scales of estimation; tracking horizontal movement of carbon; attributing changes in carbon stocks and fluxes to specific activities or entities; cross-sectoral accounting for life cycle analyses and decision-making associated with carbon management strategies; estimates of uncertainty and inclusion of redundancy for increased confidence; and generating data output that is useful to stakeholders and for policy-related purposes.

Carbon monitoring system components

- System components that are needed to meet the defined capabilities of a CMS include numerous modeling, data and accounting components.

- Obvious components include top-down and bottom-up methods of estimating carbon stocks and fluxes. However, other components needed to satisfy agreed-upon CMS capabilities should be identified prior to CMS development. These may include a network or database capable of tracking the lateral movement of carbon, and the economic forecasting of activities that influence carbon stocks and fluxes. 
and economic projections of future land use. Many of the components have been developed previously and independently of each other. A separate research focus on carbon monitoring is needed to integrate these components for sustained estimates of carbon stocks and fluxes. Once a CMS is developed, improvements in fundamental carbon cycle science can be integrated as they occur. By considering the capabilities and components discussed in this paper, and including them in the development of a CMS, carbon monitoring can improve estimates of carbon stocks and fluxes, provide sustained and consistent estimates, and help bridge the gap between carbon cycle science and carbon management.
Financial \& competing interests disclosure

Support for TO West is from the National Aeronautics and Space Administration under Carbon Monitoring System Phase 2 Project \#NNH12AU35I. Support for RM Duren is from the Jet Propulsion Laboratory, a division of the California Institute of Technology under contract to the National Aeronautics and Space Administration. The authors have no other relevant affiliations or financial involvement with any organization or entity with a financial interest in or financial conflict with the subject matter or materials discussed in the manuscript apart from those disclosed.

No writing assistance was utilized in the production of this manuscript.

\section{References}

Papers of special note have been highlighted as:

- of interest

- of considerable interest

1 Liebig M, Franzluebbers AJ, Follett RF. Managing Agricultural Greenhouse Gases: Coordinated Agricultural Research Through GRACEnet To Address Our Changing Climate. Academic Press, CA, USA (2012).

2 Lauvaux T, Schuh AE, Uliasz M et al. Constraining the $\mathrm{CO}_{2}$ budget of the corn belt: exploring uncertainties from the assumptions in a mesoscale inverse system. Atmos. Chem. Phys. 11, 20855-20898 (2011).

3 Peters W, Jacobson AR, Sweeney C et al. An atmospheric perspective on North American carbon dioxide exchange: CarbonTracker. Proc. Natl Acad. Sci. USA 104(48), 18925-18930 (2007).

4 FOA/IIASA/ISRIC/ISS-CAS/JRC. Harmonized World Soil

Database (Version 1.2). Food and Agriculture Organization, Rome, Italy; and International Institute for Applied Systems Analysis, Laxenburg, Austria (2012).

5 Huntzinger DN, Post WM, Wei Y et al. North American Carbon Program (NACP) regional interim synthesis: terrestrial biospheric model intercomparison. Ecol. Model. 232, 144-157 (2012).

6 Le Quéré C, Andres RJ, Boden T et al. The global carbon budget 1959-2011. Earth Syst. Sci. Data 5, 165-185 (2013).

7 Canadell JG, Ciais P, Gurney K, Le Quéré C, Piao S, Raupach MR. An international effort to quantify regional carbon fluxes. EOS 92 , 81-82 (2011).
8 Karl TR, Melillo JM, Peterson TC et al. Global Climate Change Impacts in the United States. Cambridge University Press, NY, USA (2009).

9 West TO. Monitoring informs management. Nat. Clim. Change 1, 399-400 (2011).

10 Denning AS, Oren R, McGuire D et al. Science Implementation Strategy for the North American Carbon Program. Report of the NACP Implementation Strategy Group of the U.S. Carbon Cycle Interagency Working Group. US Carbon Cycle Science Program, Washington, DC, USA (2005).

11 Hayes DJ, Turner DP, Stinson G et al. Reconciling estimates of the contemporary North American carbon balance among terrestrial biosphere models, atmospheric inversions and a new approach for estimating net ecosystem exchange from inventory-based data. Glob. Change Biol. 18(4), 1282-1299 (2011).

12 West TO, Bandaru V, Brandt CC, Schuh AE, Ogle SM. Regional uptake and release of crop carbon in the United States. Biogeoscience 8, 2037-2046 (2011).

- Quantifies and illustrates how crop carbon is transported throughout the USA, how this impacts carbon flux estimates, and how the transport of carbon is linked to economic supply and demand of commodities.

13 Beer C, Reichstein M, Tomelleri E et al. Terrestrial gross carbon dioxide uptake: global distribution and covariation with climate. Science 329, 834-838 (2010).

14 Jung M, Reichstein M, Margolis HA et al. Global patterns of land-atmosphere fluxes of carbon dioxide, latent heat, and sensible heat derived from eddy covariance, satellite, and meteorological observations. J. Geophys. Res. Biogeosci. 116(G3) (2011).
15 Williams CA, Collatz GJ, Masek J, Goward $\mathrm{SN}$. Carbon consequences of forest disturbance and recovery across the conterminous United States. Glob. Biogeochem. Cycl. 26(1), GB1005 (2012).

16 Schuh AE, Lauvaux T, West TO et al. Evaluating atmospheric $\mathrm{CO}_{2}$ inversions at multiple scales over a highly-inventoried agricultural landscape. Glob. Change Biology 19(5), 1424-1439 (2013).

17 Miles NL, Richardson SJ, Davis KJ et al. Large amplitude spatial and temporal gradients in atmospheric boundary layer $\mathrm{CO}_{2}$ mole fractions detected with a tower-based network in the US upper Midwest. J. Geophys. Res. Biogeosci. 117, G01019 (2012).

- An evaluation and correlation among atmospheric $\mathrm{CO}_{2}$ measurements, inventorybased modeling and satellite-based monitoring in midwestern USA.

18 US EPA. Inventory of US Greenhouse Gas Emissions and Sinks: 1990-2012. EPA 430-R12-001. US Environmental Protection Agency, Washington, DC, USA (2012).

19 Heath LS, Smith JE, Skog KE, Nowak D, Woodall C. Managed forest carbon estimates for the US greenhouse gas inventory, 1990-2008. J. Forestry 4(5), 167-173 (2011).

20 Smith JE, Heath LS, Skog KE, Birdsey RA. Methods for Calculating Forest Ecosystem and Harvested Carbon with Standard Estimates for Forest Types of The United States. General Technical Report NE-343 (2006).

21 USDA. US Agriculture and Forestry Greenhouse Gas Inventory: 1990-2008.

Technical bulletin no. 1930. US Department of Agriculture, Office of the Chief Economist, Climate Change Program Office, Washington, DC, USA (2011). 
22 King AW, Dilling L, Zimmerman GP et al. The First State Of The Carbon Cycle Report (SOCCR). National Oceanic and Atmospheric Administration, National Climatic Data Center, NS, USA (2007).

-. An initial synthesis of carbon sources and sinks in North America. In theory, such syntheses could be conducted regularly and automatically using a carbon monitoring system.

23 King AW, Hayes DJ, Huntzinger DN, West TO, Post WM. North America carbon dioxide sources and sinks: magnitude, attribution, and uncertainty. Front. Ecol. Environ. 10, 512-519 (2012).

24 IPCC. IPCC Guidelines For National Greenhouse Gas Inventories (Volume 3). Intergovernmental Panel on Climate Change, Hadley Centre, Bracknell, UK (1996).

25 IPCC. IPCC Guidelines For National Greenhouse Gas Inventories (Volume 4). Intergovernmental Panel on Climate Change, Institute for Global Environmental Strategies, Kanagawa, Japan (2006).

26 Plassmann K. Accounting for carbon removals. Nat. Clim. Change 2, 4-6 (2012).

27 Searchinger TD, Hamburg SP, Melillo J et al. Fixing a critical climate accounting error. Science 326(5952), 527-528 (2009).

28 Chapin FS, Woodwell GM, Randerson JT et al. Reconciling carbon-cycle concepts, terminology, and methods. Ecosys. 9, 1041-1050 (2006).

29 Hayes D, Turner D. The need for 'apples-toapples' comparisons of carbon dioxide source and sink estimates. EOS 93(41), 404-405 (2012).

- Documents different accounting methods used for estimating net flux to the global atmosphere versus net flux within a given region. Terminology used in reference to these different fluxes is clarified.

30 Hurtt GC, Chini LP, Frolking $S$ et al. Harmonization of land-use scenarios for the period 1500-2100: 600 years of global gridded annual land-use transitions, wood harvest, and resulting secondary lands. Clim. Change 109, 117-161 (2011).

31 West TO, Brandt CC, Baskaran LM et al. Cropland carbon fluxes in the United States: increasing geospatial resolution of inventorybased carbon accounting. Ecol. App. 20, 1074-1086 (2010).

32 Van Oost K, Quine TA, Govers G et al. The impact of agricultural soil erosion on the global carbon cycle. Science 318, 626-629 (2007).
33 Raymond PA, Oh N-H, Turner RE, Broussard W. Anthropogenically enhanced fluxes of water and carbon from the Mississippi River. Nature 451, 449-452 (2008).

34 Peters GP, Minx JC, Weber CL, Edenhofer O. Growth in emission transfers via international trade from 1990-2008. Proc. Natl Acad. Sci. USA 108(21), 8903-8908 (2011).

35 Unger N, Bond TC, Wang JS et al. Attribution of climate forcing to economic sectors. Proc. Natl Acad. Sci. USA 107, 3382-3387 (2010).

36 Duren RM, Miller CE. Towards robust global greenhouse gas monitoring. Greenhouse Gas Measure. Manage. 1, 80-84 (2011).

37 Duren RM, Miller CE. Measuring the carbon emissions of megacities. Nat. Clim. Change 2, 560-562 (2012)

38 Lawrence PJ, Feddema JJ, Bonan GB et al. Simulating the biogeochemical and biogeophysical impacts of transient land cover change and wood harvest in the community climate system model (CCSM4) from 1850 to 2100. J. Climate 25, 3071-3095 (2012).

39 Zhang X, Izaurralde RC, Manowitz D et al. An integrative modeling framework to evaluate the productivity and sustainability of biofuel crop production systems. $G C B$ Bioenergy 2, 258-277 (2010).

40 Blackard JA, Finco MV, Helmer EH et al. Mapping U.S. forest biomass using nationwide forest inventory data and moderate resolution information. Remote Sens. Environ. 112, 1658-1677 (2008).

41 Adler PR, Del Grosso SJ, Parton WJ. Lifecycle assessment of net greenhouse-gas flux for bioenergy cropping systems. Ecolog. App. 17, 675-691 (2007).

42 Ermolieva T, Ermoliev Y, Fischer G, Jonas M, Makowski M, Wagner F. Carbon emission trading and carbon taxes under uncertainties. Clim. Change 103, 277-289 (2010).

43 Monni S, Peltoniemi M, Palosuo T, Lehtonen A, Mäkipää R, Savolainen I. Uncertainty of forest carbon stock changes - implications of the total uncertainty of GHG inventory of Finland. Clim. Change 81, 391-413 (2007).

44 Cooley D, Breidt FJ, Ogle SM, Schuh AE, Lauvaux TA. A constrained least-squares approach to combine bottom-up and topdown $\mathrm{CO}_{2}$ flux estimates. Environ. Ecol. Stat. 20(1), 129-146 (2012).

- Demonstrates how differing methods can be combined to reduce uncertainty associated with carbon flux estimates.
45 Ogle SM, Breidt FJ, Easter M, Williams S, Paustian K. An empirically based approach for estimating uncertainty associated with modeling carbon sequestration in soils. Ecolog. Model. 205, 453-463 (2007).

46 US Department of Energy. International Energy Statistics. US Department of Energy, Energy Information Administration, Washington, DC, USA (2013).

47 Gurney KR, Mendoza DL, Zhou Y et al. High resolution fossil fuel combustion $\mathrm{CO}_{2}$ emissions fluxes for the United States. Environ. Sci. Tech. 43, 5535-5541 (2009).

48 Brown MD, Escobar VM, Lovell $\mathrm{H}$. Communicating the needs of climate change policy makers to scientists. In: Human and Social Dimensions of Climate Change (Chapter 3). Chhetri N (Ed.). InTech, Rijeka, Croatia, 49-62 (2013).

49 Rice JS, Moss RH, Runci PJ, Anderson KL, Malone EL. Incorporating stakeholder decision support needs into an integrated regional Earth system model. Mitig. Adapt. Strat. Global Change 17, 805-819 (2012).

- Demonstrates how surveys of literature and stakeholders can be used to guide the development of research programs and projects.

50 Hellwinckel CM, West TO, De La Torre Ugarte DG, Perlack RD. Evaluating possible cap and trade legislation on cellulosic feedstock availability. Glob. Change Biol. Bioenerg. 2, 278-287 (2010).

51 Baker JS, Murray BC, McCarl BA, Feng S, Johansson R. Implications of alternative agricultural productivity growth assumptions on land management, greenhouse gas emissions, and mitigation potential. Amer. J. Agric. Econ. 95, 435-441 (2012).

52 Wise M, Calvin K, Thomson A et al. Implications of limiting $\mathrm{CO}_{2}$ concentrations for land use and energy. Science 324, 1183-1186 (2009).

53 Reilly J, Paltsev S, Strzepek K et al. Valuing climate impacts in integrated assessment models: the MIT IGSM. Clim. Change 117, 561-573 (2013).

54 Creutzig F, Popp A, Plevin R, Luderer G, Minx J, Edenhofer O. Reconciling top-down and bottom-up modeling on future bioenergy deployment. Nat. Clim. Change 2, 320-327 (2012). 


\section{- Websites}

101 US Department of Energy. Biological and Environmental Research, Climate and Environmental Sciences Division.

http://science.energy.gov/ber/research/cesd (Accessed 31 May 2013)

102 US Department of Agriculture. Forest Inventory and Analysis National Program. www.fia.fs.fed.us

(Accessed 31 May 2013)
103 US Department of Agriculture. Quick Stats. National Agricultural Statistics Service.

www.nass.usda.gov/Data_and_Statistics/ index.asp

(Accessed 31 May 2013)

104 FAO. FAOSTAT.

http://faostat.fao.org

(Accessed 31 May 2013)
105 National Aeronautics and Space Administration. NASA Carbon Monitoring System.

http://carbon.nasa.gov/index.html? (Accessed 31 May 2013)

106 GEOCARBON.

www.geocarbon.net

(Accessed 31 May 2013) 